\title{
EVALUATION OF STRATEGIES FOR THE DECONTAMINATION OF EQUIPMENT FOR GEOMYCES DESTRUCTANS, THE CAUSATIVE AGENT OF WHITE-NOSE SYNDROME (WNS)
}

\author{
Virginia Shelley ${ }^{1}$, Samantha Kaiser ${ }^{1}$, Elizabeth Shelley ${ }^{1}$, Tim Williams', Marcelo Kramer', \\ Katie Haman ${ }^{2}$, Kevin Keel 2 , and Hazel A. Barton ${ }^{1,3 *}$
}

\begin{abstract}
White-nose syndrome is an emerging infectious disease that has led to a dramatic decline in cave-hibernating bat species. White-nose syndrome is caused by the newly described fungal pathogen Geomyces destructans, which infects the ear, muzzle, and wing membranes of bats. Although the exact mechanism by which the fungus causes death is not yet understood, G. destructans leads to a high mortality rate in infected animals. While the primary mechanism of infection appears to be bat-to-bat transfer, it is still unclear what role human activity may play in the spread of this pathogen. Here we evaluate the effectiveness of decontamination protocols that can be utilized by speleologists to reduce the likelihood of spreading this dangerous pathogen to naïve bats or uninfected hibernacula. Our results show that pre-cleaning to remove muds and/ or sediments followed by the use of commercially available disinfectants can effectively remove $G$. destructans from caving fabrics. Alternatively, immersion in water above $50{ }^{\circ} \mathrm{C}$ for at least 20 minutes effectively destroys the fungal spores. These results have allowed the development of a decontamination protocol (http://www.fws.gov/ WhiteNoseSyndrome/cavers.html) that, when appropriately followed, can greatly reduce the likelihood of the human mediated transfer of $G$. destructans from an infected to uninfected site.
\end{abstract}

\section{INTRODUCTION}

In 2006 the bat population in Howe Caverns, a commercial cave in New York, USA, contained a large number of dead or dying bats (Blehert et al., 2009). A common link between all of the dying bats was that they had a white, powder-like substance around their muzzles, ears, and wing-membranes; this white substance caused the disease to be named White-nose Syndrome (WNS). WNS is believed to cause a greater than $70 \%$ mortality rate (range 30 to $99 \%$ ) in bat populations of infected hibernacula and has been associated with a mass bat die-off in the northeastern US, with an estimated 5.5 million deaths (USFWS, 2012). To date, eighteen states have either confirmed WNS [demonstrating bats with histological evidence of a WNS infection: (Meteyer et al., 2009)] and/ or bats that test positive for the presence of the etiological agent, the fungus Geomyces destructans. These states are Connecticut, Delaware, Kentucky, Maine, Maryland, Massachusetts, Missouri, New Hampshire, New Jersey, New York, North Carolina, Ohio, Oklahoma, Pennsylvania, Tennessee, Vermont, Virginia, and West Virginia. The fungus is also now affecting bat populations in Canada, including the provinces of New Brunswick, Nova Scotia, Ontario, and Quebec. As of December 2011, more than two hundred bat hibernacula have been affected by WNS, which has resulted in a significant decrease in cave-hibernating bat populations in the Northeast (Kunz and Tuttle, 2009). At the current rate of both mortality and spread, WNS is likely to cause the regional extinction of the little brown bat Myotis lucifugus within the next twenty years (Frick et al., 2010).

Koch's postulates were recently satisfied for G. destructans (Lorch et al., 2011), demonstrating that G. destructans was the sole agent of WNS. While this paper demonstrated that $G$. destructans could be spread directly through bat-tobat contact, airborne movement of the pathogen was inconclusive, and the role of fomites was not investigated. Whatever the mechanisms of transport, Chaturvedi et al. (2010) demonstrated that a single strain of $G$. destructans was responsible for WNS in over one hundred bats from geographically diverse regions. These investigators used random amplification of polymorphic DNA (RAPD) to demonstrate that all tested isolates had identical RAPD patterns using differential primer sets. Further evidence suggests that $G$. destructans may be an introduced pathogen is provided by the discovery of morphologically and genetically similar Geomyces strains from France

\footnotetext{
* Corresponding author: bartonh@uakron.edu

${ }^{1}$ Department of Biological Sciences, Northern Kentucky University, Highland Heights, KY 41099

${ }^{2}$ UC Davis, School of Veterinary Medicine, Dept. Pathology, Microbiology and Immunology, One Shields Ave. Davis, CA 95616

${ }^{3}$ Department of Biology, University of Akron, Akron, OH 44325
} 
(Puechmaille et al., 2010). This European fungus has since been confirmed in three additional countries: Germany, Switzerland, and Hungary (Wibbelt et al., 2010). However, DNA sequencing across a range of genes will be needed to confirm that this strain is the source of the WNS epidemic. The high mortality rates caused by WNS in the US have not been observed among European bats infected with $G$. destructans. Although the susceptibility of European bat species to WNS has not been fully evaluated, they do demonstrate different hibernation patterns, which may reflect the influence of past epidemics on the populations (Puechmaille, personal communication, 2010).

Past epizootics demonstrate the role human activity can play in the spread of animal pathogens, including foot-andmouth disease virus (Savill et al., 2006) and the chytrid fungus Batrachochytrium dendrobatidis (Daszak et al., 2000). In these epidemics, human activity has contributed to the spread of the pathogen, while altered behavior and disinfection have been shown to limit or prevent its dissemination (Savill et al., 2006, Webb et al., 2007). At this time, we have no understanding of $G$. destructans viability in the environment or how many fungal cells or spores are sufficient to infect a bat or colonize a cave environment. Until this information is available, it is critical that decontamination protocols are used to eliminate the possibility of WNS spread by human activity. In this paper we assess potential physical and chemical methods to decontaminate the fabrics and materials used by speleologists. Our results demonstrate that safe and effective methods of disinfection are possible to limit the anthropomorphic spread of $G$. destructans.

\section{Materials And Methods}

\section{Fungal Strains and Growth Conditions}

The following strains were obtained from the American Type Culture Collection (ATCC; Manassas, Virginia): Geomyces pannorum var pannorum (ATCC 16222), Aspergillus brasiliensis (née niger, ATCC 9642) and Penicillium pinophilum (ATCC 9644). These species were grown in Geomyces media ( $40 \mathrm{~g}$ dextrose, $10 \mathrm{~g}$ peptone $\mathrm{L}^{-1}$ ) to which $2 \%$ agarose was added as a gelling agent for solid media. Geomyces destructans was obtained from a little-brown bat collected in Hell Hole Cave, West Virginia, sent to the SCWDS and confirmed by cell morphology, PCR, and an invasive histology diagnostic of WNS. Growth was carried out at room temperature (RT) for all strains except $G$. destructans, which was grown at $7{ }^{\circ} \mathrm{C}$. Mueller-Hinton agar for disk-diffusion assays was obtained from BD Difco/BBL (Franklin Lakes, New Jersey).

\section{Spore Suspensions}

Conidiospores (spores) from all fungi were harvested from fungal plates in liquid Geomyces media using the American Society for Testing and Materials protocol G2109 (ASTM, 2002), with $0.1 \%$ sodium dioctyl sulfosuccinate
(DSS) as a wetting agent. DSS was tested for toxicity against each of the fungal strains and demonstrated no inhibitory effect on growth or spore germination. Spore suspensions were counted using a hemocytometer and resuspended in liquid Geomyces media to a stock concentration of $1 \times 10^{6}$ spores $\mathrm{mL}^{-1}$. Once made, all spore suspensions were stored at $4{ }^{\circ} \mathrm{C}$ and used within four days.

\section{Survival Assays}

Three assays were carried out on spore suspensions to determine spore killing (sporicidal) or fungal growth inhibition (fungistatic) activity of treatments. All assays were carried out in triplicate and the average of each treatment was recorded.

Sporocidal assay - Suspensions of spores at $1 \times 10^{3}, 1 \times$ $10^{4}$ and $1 \times 10^{5}$ spores $\mathrm{mL}^{-1}$ were filtered onto a $25-\mathrm{mm}$ diameter 5.0 $\mu \mathrm{m}$ PFTE membrane (Cat \# LSWG02500, Millipore, Billerica, Massachusetts; Geomyces spores are $\sim 17 \mathrm{~mm} \varnothing$ ) using a sterile glass membrane filtration unit (Millipore Cat \# XX1002502). While still in the filtration unit, the membranes were exposed to chemical treatment for ten minutes, washed three times with $10 \mathrm{~mL}$ sterile distilled water, then aseptically removed and placed on culture media for growth. Following all treatments, the membrane plates were incubated until colonies were observed: up to six days for G. pannorum and nine days for the slower growing $G$. destructans. Germination/ outgrowth rates were calculated as the number of colonies divided by the total number of viable spores applied; viability was determined from untreated controls.

Disk diffusion assays - Approximately $1 \times 10^{4}$ spores of $G$. pannorum or $G$. destructans were streaked across the entire surface of either a Mueller-Hinton or Geomycesmedia plate. The agar plate was allowed to dry until surface moisture was no longer evident, and a $6 \mathrm{~mm}$ sterile Whatman paper disk (Whatman, Piscataway, New Jersey) soaked in a single test chemical was placed directly on the plate, using aseptic techniques. Plates were allowed to incubate until confluent fungal growth was observed, and the diameter of the zone of inhibition was measured. To examine the effectiveness of disinfection on G. pannorum in the presence of other materials, a top agar containing Geomyces media, $1 \%$ agar, and $2 \%$ of the test material (organic material, muds and sediment) was added. This top agar had been autoclaved and was poured over the surface of Geomyces-media plates to a depth of $2 \mathrm{~mm}$. Testing was then carried out using the standard disk-diffusion assay. The organic material, mud and sediment (weathered sandstone) was obtained of a Kentucky cave within the Ste. Genevieve Formation.

\section{Chemicals Tested for Potential Effectiveness \\ Against GEOMYCES SPP.}

Lab grade chemicals were obtained from Sigma-Aldrich (St. Louis, Missouri). The off-the-shelf chemicals were obtained from local retail stores. Household bleach

2• Journal of Cave and Karst Studies, April 2013 
(Clorox, 6\% $\mathrm{HOCl}$ ) was diluted $1: 10(0.6 \%)$ prior to use in all the assays described. The chemical formulations for products evaluated were obtained from publically available material safety data sheets (MSDS). Initial screening was carried out using the disk diffusion assay (Bauer 1966) on both Mueller-Hinton and Geomyces media plates.

\section{Heat Treatments of Spores}

\section{Dry-Air Treatments}

Suspensions of $10^{3}-10^{4}$ G. pannorum or G. destructans spores were placed on membrane filters as previously described, placed in sterile petri dishes and exposed to air temperatures of $50{ }^{\circ} \mathrm{C}, 60{ }^{\circ} \mathrm{C}, 70{ }^{\circ} \mathrm{C}, 80{ }^{\circ} \mathrm{C}, 90{ }^{\circ} \mathrm{C}$, or $100{ }^{\circ} \mathrm{C}$ for fifteen minutes. The membrane filters were then placed on Geomyces media and incubated at $7{ }^{\circ} \mathrm{C}$ for three weeks.

\section{Submersion Treatments}

One $\mathrm{mL}$ of a $3 \times 10^{5}$ per $\mathrm{mL}$ spore suspension of $G$. pannorum or $G$. destructans was placed in conical centrifuge tubes and immersed in water at $30{ }^{\circ} \mathrm{C}, 40{ }^{\circ} \mathrm{C}, 50{ }^{\circ} \mathrm{C}, 60{ }^{\circ} \mathrm{C}$, or $70{ }^{\circ} \mathrm{C}$ for twenty minutes. A $100 \mu \mathrm{L}$ aliquot of the suspension was spread on an SDA plate and incubated at $7{ }^{\circ} \mathrm{C}$ for forty days, with colony numbers, in a randomly placed $4 \times 4 \mathrm{~cm}$ grid, recorded at days seven and forty. All heat treatments were done in replicates of three.

\section{Autoclaving}

Preparations of G. pannorum and $G$. destructans spores and hyphae were heated to $121{ }^{\circ} \mathrm{C}$ at $15 \mathrm{psi}(103 \mathrm{kPa})$ for fifteen minutes using an AMSCO 3013 autoclave sterilizer (STERIS Corporation, Mentor, Ohio). All heat treatments were done in replicates of three. A variety of caving equipment, such as oversuits, helmets, and ropes were treated in the autoclave under the same conditions.

\section{Surface Treatment Assays}

New nylon caving fabrics appeared to carry a charge from the nylon or contained water-repellent coatings, preventing the attachment or penetration of spore suspensions. As a result, these materials were not used. Instead a 1000-denier Cordura caving oversuit manufactured by Warmbac (Glastonbury, England) that had been heavily used for four years was used in the surface-treatment assays. One-inch tubular webbing, Sterling $11 \mathrm{~mm}$ HTP polyester rope, and Sterling $11 \mathrm{~mm}$ Superstatic nylon rope were obtained from Sterling Rope (Biddeford, Maine).

\section{Surface Sterilization Assays}

Treatment assays were carried out according to the standard protocol for testing the resistance of synthetic polymeric materials to fungi (ASTM G21-09; ASTM, 2002). Briefly, sections of test fabric were cut into roughly 3 $\times 3 \mathrm{~cm}$ squares, while rope and webbing sections were cut into approximately $3 \mathrm{~cm}$ pieces using a heated $1 \mathrm{~mm}$ wire. All samples were autoclaved prior to treatment, with sterile control samples demonstrating no fungal growth. Surfaces were sprayed with $250 \mu \mathrm{L}$ of a $1 \times 10^{6}$ spores per $\mathrm{mL}$ suspension, allowed to air-dry for one hour to overnight, depending on the material, and were then exposed to the treatment. After exposure, the material was washed twice by immersion in $500 \mathrm{~mL}$ of sterile distilled water, allowed to airdry, and then either pressed or rolled (in the case of rope) onto the surface of solid Geomyces media to deposit spores. The total number of colonies per plate was counted to determine the number of colonies divided by the number of viable applied spores. In the case of adherent fungi, which were not transferred from the fabric to the media, the remaining material was placed in $40 \mathrm{~mL}$ Geomyces media. Any growth indicated spore survival following disinfection.

\section{Rope-Strength Testing}

To test the strength of safety equipment following treatment, $4 \mathrm{~m}$ lengths of rope or $1 \mathrm{~m}$ sewn webbing loops were treated under the conditions deemed most effective at decontaminating ropes: washing in a front-loading washing machine with the manufacturer's recommended concentration of Woolite detergent, rinsing with water, soaking in a 1:64 dilution of Lysol IC for ten minutes, and rinsing twice in water. That concentration of Lysol IC was used to chemically stress the material, although we showed that a 1:128 dilution is sufficient for disinfection. To test whether this altered the strength of the rope or webbing, three replicate samples were subjected to one or five rounds of treatment (Woolite wash, rinse, treat with Lysol IC, rinse twice). The strength of these materials was then tested at Sterling Rope on a custom-built pull apparatus using a $60 \mathrm{kN}$ hydraulic ram according to the Cordage Institute standard 1801 and calibrated by American Calibration, Inc. (ISO/IEC 17025 accredited, Crystal Lake, Illinois). Pull data was captured by means of a load cell attached to a PAXS strain gage meter (Red Lion Controls, York, Pennsylvania) with a sample rate of $20 \mathrm{~Hz}$. Statistical analysis was performed on grouped samples using a paired $t$-test with a $p$-value of 0.05 .

\section{RESUlTS}

In order to determine the effectiveness of all treatments, we began by autoclaving G. pannorum and G. destructans cultures. These tests demonstrated that autoclaving at 15 psi (103 kPA) for fifteen minutes killed 100\% of Geomyces spores and hyphae, even at fairly high concentrations (e.g., $1 \times 10^{7}$ spores per $\mathrm{mL}$ ). Most caving equipment did not withstand autoclave conditions: ropes became permanently fixed in shape, oversuits became friable, and the lining and cradle fabrics of helmets melted, although the plastics retained their shape. Given the gross physical changes, no attempt was made to determine how autoclaving affected the strength of these fabrics.

Spores of G. pannorum, A. brasiliensis, and P. pinophilum were all resistant to killing by baking (dry heat) above $50{ }^{\circ} \mathrm{C}$ (Table 1). At $50{ }^{\circ} \mathrm{C}$, germination and growth of $G$. 
Evaluation of Strategies For the DeContamination of EQuipment for GEomyces destructans, the Causative agent of White-Nose SYNDROME (WNS)

Table 1. Number of viable spores following 15 minutes of dry-air heating at $50{ }^{\circ} \mathrm{C}$.

\begin{tabular}{|c|c|c|c|c|c|}
\hline \multirow[b]{2}{*}{ Species } & \multirow[b]{2}{*}{ Spores/mL } & \multicolumn{4}{|c|}{ Treatment } \\
\hline & & Control $^{\mathrm{a}}$ & $5 \mathrm{~min}$ & $10 \mathrm{~min}$ & $15 \mathrm{~min}$ \\
\hline \multirow[t]{2}{*}{ Geomyces pannorum } & $1 \times 10^{4}$ & TNTC & TNTC & TNTC & 21 \\
\hline & $1 \times 10^{3}$ & TNTC & TNTC & NG & $\mathrm{NG}$ \\
\hline \multirow[t]{2}{*}{ Aspergillus brasiliensis } & $1 \times 10^{4}$ & TNTC & TNTC & TNTC & TNTC \\
\hline & $1 \times 10^{3}$ & TNTC & TNTC & TNTC & TNTC \\
\hline \multirow[t]{2}{*}{ Penicillium pinophilum } & $1 \times 10^{4}$ & TNTC & TNTC & TNTC & TNTC \\
\hline & $1 \times 10^{3}$ & TNTC & TNTC & TNTC & 2 \\
\hline
\end{tabular}

${ }^{a}$ Untreated spore suspension.

TNTC $=$ Too numerous to count

$\mathrm{NG}=$ No growth

pannorum spores was $82.7 \%$ of the untreated controls. At the same temperature, $35.3 \%$ of $G$. destructans spores were able to germinate by day seven. When the treatments were increased to $70{ }^{\circ} \mathrm{C}$, no $G$. destructans spores germinated. Nonetheless, the spores of $G$. destructans were not as resistant to immersion in hot water. When $G$. destructans spore suspensions were treated at $50{ }^{\circ} \mathrm{C}$ for even two minutes, germination of spores after seven days was eliminated (Fig. 1), while unheated controls had abundant growth (data not shown). Exposure to $40{ }^{\circ} \mathrm{C}$ and $45^{\circ} \mathrm{C}$ also reduced the viability of $G$. destructans spores (Fig. 1), but by day forty, viable colonies were observed. Repeated

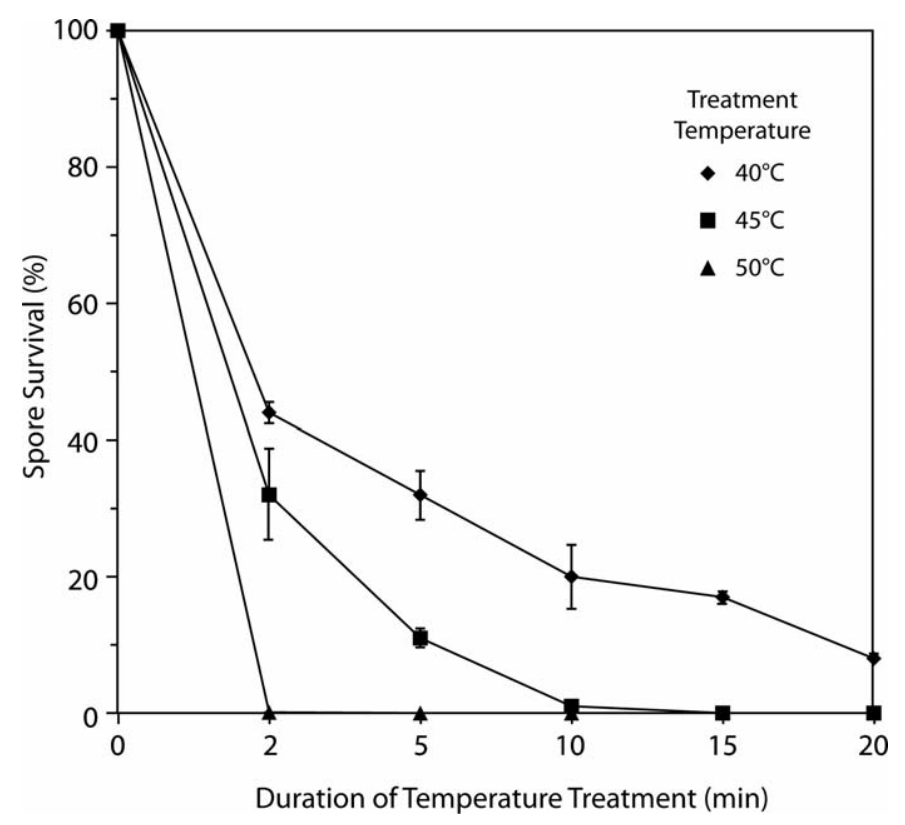

Figure 1. Effects of immersive heating on spore suspensions of $G$. destructans. Spore suspensions were heated in a water bath, then plated on culture media and incubated at $6^{\circ} \mathrm{C}$ for seven days. The average spore growth (percentage) compared to the original inoculum of three separate assays is shown. Error bars indicate the standard deviation from this average. Inhibited growth of $G$. destructans was confirmed for up to forty days post-treatment. assays demonstrated that only immersion at $\geq 50{ }^{\circ} \mathrm{C}$ for a minimum of twenty minutes resulted in sterilization of $G$. destructans spores.

Commercially available cleaning agents, disinfectants, and chemicals (Table 2) were screened for their ability to either kill Geomyces spores (sporicidal) or limit the germination and growth of the fungus (sporostatic). In all, forty-four commercially available disinfection products were screened against $G$. pannorum, A. brasiliensis, and $P$. pinophilum (Table 2). As expected, some traditional disinfecting agents, such as hydrogen peroxide $\left(\mathrm{H}_{2} \mathrm{O}_{2}\right)$, crystal violet, and iodine demonstrated good inhibition of fungal growth. Other effective chemicals contained quaternary ammonium compounds as a disinfectant, including Lysol IC (n-alkyl (C8-18) dimethylbenzylammonium chloride), Formula 409 [n-alkyl (C12-16) dimethylbenzyl ammonium chloride], and Oust Surface and Air cleaner (n-Alkyl dimethyl benzyl ammonium saccharinate). Lysol IC comes in concentrated form (20 to $25 \%$ ), and our work demonstrates that a $1: 128$ dilution $(0.15$ to $0.20 \%$ final concentration) of Lysol IC is the minimum effective concentration. Agents containing a detergent also appeared to be effective, including Dawn, Ivory, and Palmolive products, all of which contain ionic and non-ionic detergents. Agents that contain both a disinfectant and a detergent, such as Clorox Toilet Bowl Cleaner (disinfectant: $\mathrm{NaClO} 1$ to $5 \%$ ), Tide with Bleach (disinfectant: benzenesulfonic acid 10\%), Woolite (disinfectant: benzenesulfonic acid), and Dawn Antibacterial Dish Soap (disinfectant: Triclosan, undisclosed percent), are also effective against the growth of Geomyces species.

Other chemicals demonstrated less effectiveness. Alcohols did not demonstrate strong activity against $G$. pannorum, either directly (chemical-grade $70 \%$ alcohol) or in the following products: Purell Hand Sanitizer, Quick Care, Listerine, Exo Balance, and Cal Stat. Acids and bases also failed to demonstrate any significant effect against Geomyces growth, including those found in Grease Lightning, Cascade Gel, Jump Ultra Fabric Softner, and food-grade vinegar. Finally, Tilex Fresh Shower, which contains the cation-chelating agent ethylenediaminetetraacetic acid (EDTA), Seventh Generation Fabric Softner,

4 Journal of Cave and Karst Studies, April 2013 
Table 2. Resistance of fungal spores to various disinfectants based on Kirby-Bauer disk-diffusion assays.

\begin{tabular}{|c|c|c|c|}
\hline \multirow[b]{2}{*}{ Disinfectant/ Chemical Agent } & \multicolumn{3}{|c|}{ Zone of Inhibition, mm } \\
\hline & G. pannorum & Aspergillus & Penicillium \\
\hline crystal violet stain & 39 & 20 & 28 \\
\hline Dawn Simple Pleasures & 35 & 27 & 32 \\
\hline Chlorox Toilet Bowl Cleaner & 35 & 28 & 24 \\
\hline Palmolive pure and clean & 34 & 24 & 18 \\
\hline Tide with Bleach & 34 & 35 & 25 \\
\hline Oust Surface and Air & 34 & 10 & 14 \\
\hline Meyer's Clean Day & 34 & 24 & 27 \\
\hline Hydrogen Peroxide (3\%) & 34 & NZ & $\mathrm{NZ}$ \\
\hline Dawn Dish Liquid & 33 & 27 & 33 \\
\hline anti-bacterial hand soap & 31 & 21 & 13 \\
\hline Woolite & 31 & NZ & 20 \\
\hline Penguin Sport-Wash & 30 & 25 & 26 \\
\hline Formula 409 & 29 & 25 & 13 \\
\hline Ivory Hand soap & 28 & NZ & 12 \\
\hline iodine & 25 & 12 & NZ \\
\hline Cascade Gel & 25 & NZ & NZ \\
\hline Pine-Sol & 25 & 9 & 29 \\
\hline Hibiclens & 24 & 18 & 14 \\
\hline Scope & 22 & NZ & $\mathrm{NZ}$ \\
\hline Vick's Early Defense & 18 & 17 & 16 \\
\hline $70 \%$ ethanol & 18 & 4 & 10 \\
\hline Scotchguard Oxy Pet Spot Stain Cleaner & 17 & NZ & NZ \\
\hline household bleach $(1: 10)$ & 16 & NZ & 18 \\
\hline decolorizer & 14 & 26 & NZ \\
\hline Lysol IC Disinfectant Cleaner (1:128) & 15 & NZ & NZ \\
\hline Tabasco & 13 & - & - \\
\hline Vesphene Disinfectant & 13 & - & - \\
\hline Hydrogen Peroxide $(0.3 \%)$ & 12 & - & - \\
\hline SporiCLEAN & 11 & - & - \\
\hline Grease Lightning & 9 & - & - \\
\hline vinegar & 9 & - & - \\
\hline Cascade Actionpack & $\mathrm{NZ}$ & - & - \\
\hline Purell Hand Sanitizer & NZ & - & - \\
\hline silver nitrate & $\mathrm{NZ}$ & - & - \\
\hline Quick Care & $\mathrm{NZ}$ & - & - \\
\hline Listerine & NZ & - & - \\
\hline Cal Stat & NZ & - & - \\
\hline Tilex Fresh Shower & $\mathrm{NZ}$ & - & - \\
\hline Jump Ultra Fabric Softner & $\mathrm{NZ}$ & - & - \\
\hline Seventh Generation Fabric Softner & NZ & - & - \\
\hline PureGreen 24 & NZ & - & - \\
\hline Virkon $(1 \%)$ & NZ & - & - \\
\hline Exo Balance & $\mathrm{NZ}$ & - & - \\
\hline
\end{tabular}

$\mathrm{NZ}=$ No zone of inhibition (growth up to disk).

Dashes indicate test not done.

which contains the palm-oil extract dihydrogenated palmoylethyl hydroxyethylmonium methosulfate, and Virkon, which contains potassium peroxymonosulfate, all failed to demonstrate any effect on fungal growth. Based on some discussion within the WNS scientific community, we also examined products that contained silver as a disinfectant [PureGreen24 (colloidal silver) and silver nitrate (1\% $\left.\mathrm{AgNO}_{3}\right)$ ], as well as enzymatic cleaners such as SporiCLEAN; however, none of these products demonstrated significant antifungal activity.

Journal of Cave and Karst Studies, April 2013 • 5 



SYNDROME (WNS)

Table 3. Comparative resistance of $G$. pannorum and $G$. destructans spores to disinfectants based on the diskdiffusion assays.

\begin{tabular}{lccc}
\hline & \multicolumn{3}{c}{ Zone of Inhibition, mm } \\
\cline { 2 - 3 } & Geomyces pannorum & & Geomyces destructans \\
\cline { 2 - 3 } Treatment & Day 7 & Day 30 & Day 30 \\
\hline control & $\mathrm{NZ}$ & $\mathrm{NZ}$ & $\mathrm{NZ}$ \\
Lysol & 23 & 23 & 31 \\
bleach (1:10) & 67 & 45 & $\mathrm{NG}$ \\
ethanol (70\%) & 11 & $\mathrm{NZ}$ & 7 \\
Woolite & 27 & 24 & 44 \\
Formula 409 & 27 & 24 & 31 \\
\hline
\end{tabular}

$\mathrm{NZ}=$ No zone of inhibition (growth up to disk).

$\mathrm{NG}=$ Fungus was completely cleared from the plate.

Following this preliminary screen, the agents chosen for further study either demonstrated effectiveness against $G$. pannorum (Woolite, Formula 409) or had known activity against fungi (Lysol IC, household bleach, and alcohol). A number of agents that demonstrated strong antifungal activity in the G. pannorum assays were not examined due to practical disinfection issues, such as staining of materials (crystal violet and iodine), the concentrations necessary to generate antifungal activity (Dawn Dish Soap), or potential damage to fabrics (Clorox Toilet Bowl Cleaner). Before additional, more extensive testing was carried out, Lysol IC, Woolite, Formula 409, household bleach, and 70\% alcohol were also tested for their effectiveness against the pathogen $G$. destructans in a disk-diffusion assay. The results for $G$. destructans and $G$. pannorum were similar, although $G$. destructans appeared to be more susceptible to the same chemical treatments as G. pannorum (Table 3), confirming the choice of these compounds.

Disk-diffusion assays only demonstrate the susceptibility of an organism to grow in the presence of a particular disinfectant; they do not demonstrate the effectiveness of that agent as an exposure-based disinfectant. We therefore used the filtration assay to test the effectiveness of exposure to Formula 409, Woolite, Lysol IC, bleach, and 70\% ethanol in preventing $G$. pannorum and $G$. destructans germination. Due to the sub-leathal damage that can occur from such treatments, $G$. destructans spores were allowed to recover for up to forty days following exposure (Russell, 1990). The results (Table 4) demonstrated that direct exposure to household bleach (1:10), Formula 409, and Lysol IC (1:128) completely inactivated Geomyces spores following exposure. Woolite demonstrated a reduced level of sporicidal activity (Table 3 ), suggesting that the activity of this agent in disk-diffusion assays is fungistatic. Alcohol did not demonstrate any effective killing of fungal spores in these assays (Table 4).

While these approaches demonstrate the effectiveness of chemical disinfection in the laboratory, they do not necessarily translate to efficient disinfection in the field. We therefore examined factors that may affect the effectiveness of these disinfectants under real-world conditions.

Cave explorers use a number of different fabrics due to their durability and abrasion resistance, as well as critical life-support equipment, including rope, webbing, and harnesses. The structure of these fabrics, with multiple niches for spore attachment, protection, and chemical absorption, may affect the penetration and effectiveness of chemical disinfectants. Therefore, we took fabrics used by cavers and examined disinfection efficiency following the direct application of fungal spores to the surface. Approximately $2.5 \times 10^{4}$ spores per $\mathrm{cm}^{2}$ were applied to ballistic nylon (used under cave conditions), and treatment was carried out with Formula 409, household bleach (1:10), and Lysol IC (1:128) for 5, 10, and 15 minutes. The results (Table 5) demonstrated that fungal spores are effectively and reproducibly disinfected on these surfaces with no remaining viable spores when treatment is applied for a minimum of 10 minutes. Woolite greatly reduced the number of viable spores, but did not act as a disinfectant in this assay, while alcohol had comparatively little activity.

During exploration, caving fabrics become covered in mud, clay, or other sediments and organic debris, which could limit the effectiveness of disinfecting agents against fungal spores (Russell, 1990). To this end, organic material,

Table 4. Sporicidal activity of disinfectants against G. destructans compared to G. pannorum following a 10-minute exposure.

\begin{tabular}{lccccccccc}
\hline & & \multicolumn{5}{c}{ Treatments } \\
\cline { 3 - 9 } Species & $\begin{array}{c}\text { Days after } \\
\text { Treatment }\end{array}$ & spores/mL & control & Formula 409 & Woolite & $\begin{array}{c}\text { Lysol } \\
(1: 100)\end{array}$ & $\begin{array}{c}\text { bleach } \\
(1: 10)\end{array}$ & $\begin{array}{c}\text { ethanol } \\
(70 \%)\end{array}$ \\
\hline G. pannorum & 4 & $1 \times 10^{4}$ & 56 & 49 & 26 & 13 & 0 & 6 \\
& 5 & $1 \times 10^{4}$ & TNTC & 53 & 32 & TNTC & 0 & 35 & TNTC \\
G. destructans & 6 & $1 \times 10^{4}$ & TNTC & TNTC & TNTC & TNTC & 0 & 0 & 177 \\
& 7 & $1 \times 10^{4}$ & TNTC & 0 & 0 & 0 & 0 & 0 & TNTC \\
& 9 & $1 \times 10^{4}$ & TNTC & 0 & 0 & 0 & TNTC \\
\hline
\end{tabular}

TNTC $=$ Too numerous to count.

6• Journal of Cave and Karst Studies, April 2013

Journal of Cave and Karst Studies cave-75-01-01.3d 21/1/13 13:26:14 6 Cust \# 2011LSC0249 
Table 5. Effectiveness of Disinfectants against G. pannorum in the Presence of Various Cave Sediments.

\begin{tabular}{|c|c|c|c|c|c|c|c|c|}
\hline \multirow[b]{3}{*}{ Disinfectant } & \multicolumn{4}{|c|}{ Disk Diffusion } & \multicolumn{4}{|c|}{ Fabric Treatment (Rope) } \\
\hline & \multicolumn{4}{|c|}{ Zone of Inhibition, mm } & \multicolumn{4}{|c|}{ Colonies } \\
\hline & Control & Clay & Sand & Silt & Control & Clay & Sand & Silt \\
\hline Bleach $(1: 10)$ & 67 & 12 & $\mathrm{NZ}$ & NZ & TNTC & 0 & 11 & 9 \\
\hline Lysol IC (1:128) & 23 & NZ & 12 & 12 & TNTC & 0 & 0 & 0 \\
\hline Formula 409 & 27 & 32 & NZ & NZ & TNTC & 0 & 0 & 0 \\
\hline
\end{tabular}

TNTC $=$ Too numerous to count

$\mathrm{NZ}=$ No zone of inhibition (growth up to disk)

mud, and sediment were added to the disk-diffusion assays to determine how great an effect the presence of these materials could have on disinfection. The results (Table 5) demonstrate that cave detritus can have a dramatic impact on the effectiveness of these disinfectants. We therefore repeated our cave fabric disinfection protocol with mud applied along with the fungal spores. The results (Table 5) demonstrated that these substances also dramatically reduced the effectiveness of disinfection on these surfaces, arguing for a pre-cleaning treatment prior to disinfection.

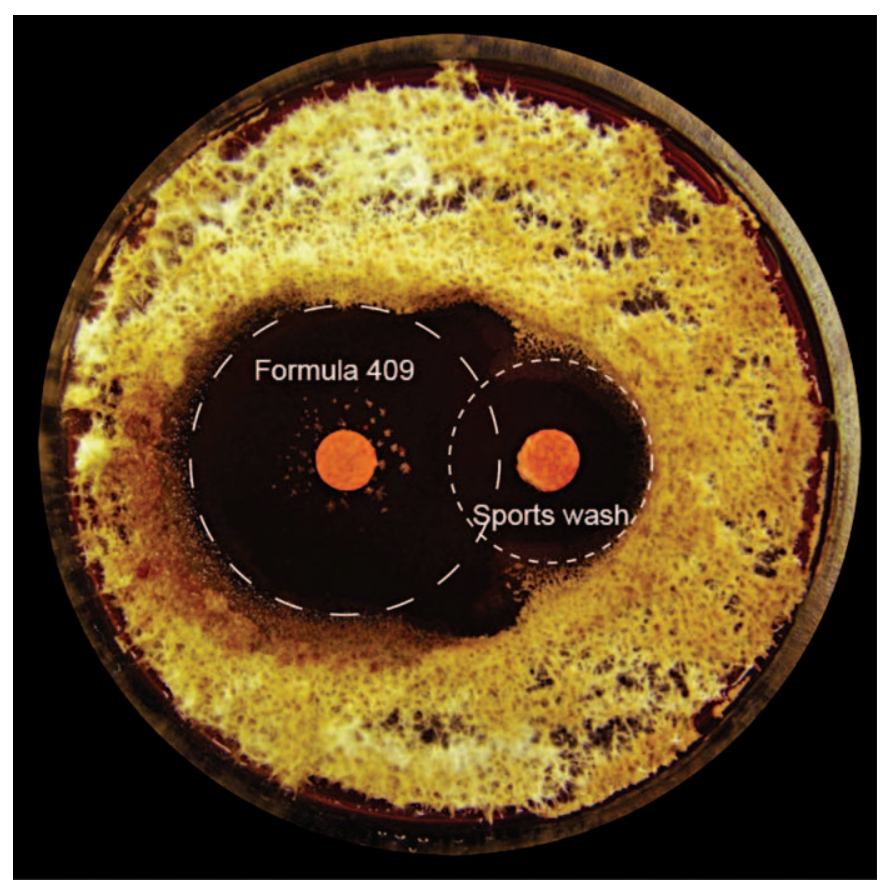

Figure 2. Synergistic effects of multiple treatments on the growth of $G$. pannorum. Disk diffusion assays were set up using various combinations of disinfecting agents. The combination of Formula 409 (left disk) and Penguin SportWash (right disk) is shown. While a zone where each chemical prevents the growth of the fungus around each disk is observed, the combination of the two chemicals generates a greater zone of inhibition than each alone (larger zone between the two disks).
To test this, we carried out a disk diffusion assay to determine if specific detergents and disinfectants were compatible; such combinations can often be problematic as cationic disinfectants and anionic detergents can bind to each other, precipitate, and negate the effect of both products. In these assays we compared the inhibition of fungal growth by combinations of both Woolite and Meyer's Clean Day washing detergents with Formula 409, household bleach (1:10), and Lysol IC (1:128). The results (for example, Fig. 2) suggested that these products lead to a greater inhibition of fungal growth together than each does individually. It therefore appears that a pre-wash with a detergent such as Woolite can remove inhibitory substances while contributing to overall disinfection.

In addition to fabrics, speleologists use a number of pieces of critical life support equipment, including harnesses, webbing, and ropes. The nylon in this equipment gives the ropes or webbing strength; however, it is also susceptible to ionic attack, by substances such as bleach, which can damage the structural integrity and strength of the material. Consequently, we wanted to examine the ability of disinfection protocols to remove or kill spores on this material without harming its strength. Given the negative potential effects of bleach on nylon, we examined the ability of Woolite (which is traditionally used by speleologists to wash ropes) and Lysol IC (which can be made up in large volumes) to disinfect sewn webbing and nylon ropes. Treatment was carried out by washing in Woolite, rinsing with sterile water, soaking in a 1:64 dilution of Lysol IC for ten minutes, and rinsing twice in sterile water. The results demonstrated $100 \%$ killing of 2.5 $\times 10^{5}$ spores applied to rope and webbing samples (Table 5). A higher concentration of Lysol IC (1:64) was used to chemically stress the material, although a 1:128 dilution has been shown to be $100 \%$ effective in this assay. To test whether this altered the strength of the webbing or rope, we treated samples of one-inch tubular webbing, Sterling $11 \mathrm{~mm}$ HTP rope, and Sterling $11 \mathrm{~mm}$ Superstatic rope, for one or five rounds of treatment. The strength of these materials was then tested, and the average breaking strength (in kN) was recorded (Fig. 3). Similar rope tests have not been carried out on samples returned to other rope manufacturers despite repeated requests.

Journal of Cave and Karst Studies, April 2013•7 
Evaluation of Strategies for the DeContamination of EQuipment for Geomyces destructans, the Causative agent of White-Nose SyndRome (WNS)

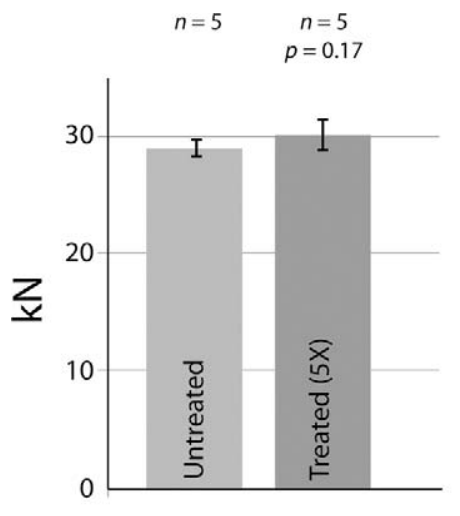

$27 \mathrm{~mm}$ Tubular Webbing

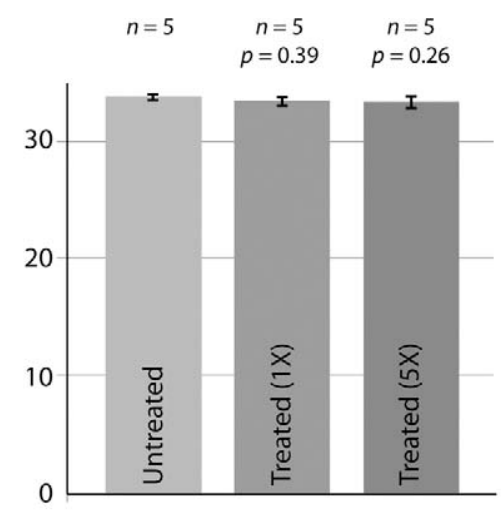

$11 \mathrm{~mm}$ HTP Static

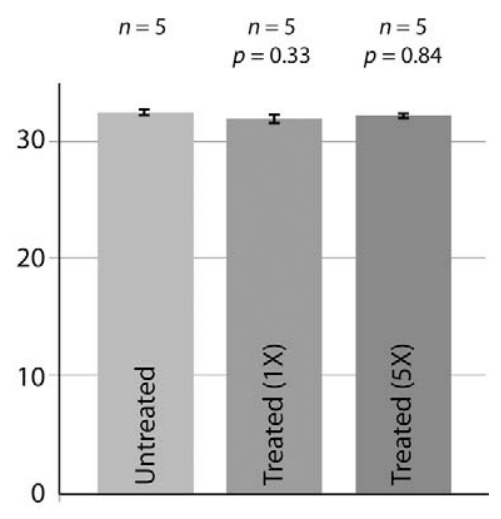

$11 \mathrm{~mm}$ Superstatic

Figure 3. Rope and webbing post-treatment strength tests. Samples of rope and webbing were treated in triplicate with either one or five rounds of chemical treatment. The samples were then subjected to strength tests to determine the average breaking strength (in $\mathrm{kN}$ ). The standard deviation of the combined results is shown as error bars. Based on a paired t-test $(p=0.05)$ there was no significant difference between the strength of the treated and untreated samples.

\section{Discussion}

We carried out our preliminary assays in the nonpathogenic G. pannorum due to the ease of cultivation and comparatively short generation time for this species in the laboratory (five days to confluent growth versus approximately one month for $G$. destructans); however, to confirm the effectiveness of our decontamination protocols, we repeated key assays with $G$. destructans. Our results demonstrated a strong correlation between the effectiveness of these agents in $G$. pannorum and $G$. destructans, arguing for the appropriateness of G. pannorum as a model organism for preliminary assay development. We also chose to concentrate our assays on spores, the more resistant form of the G. destructans fungus (Deacon, 2005). Conidiospores are made by fungi for dispersal of the parent organism and, as such, are intrinsically resistant to environmental stressors such as UV and desiccation (Deacon, 2005, Gottlieb, 1950, Russell, 1990). Indeed, this can be seen by the relative resistance of these spores to both heat treatments and alcohols, and that heat stress actually promotes the germination and outgrowth of fungal spores (Table 1), even in the case of this psychrophilic fungi (Deacon, 2005, Russell, 1990).

Our results demonstrate that certain compounds, such as Formula 409 or bleach, are viable means of $G$. destructans disinfection to prevent the spread of WNS. Given the ineffectiveness of alcohols, protocols that suggest cavers should wipe exposed skin with alcohol swabs or alcohol-based hand sanitizer should be met with skepticism. The fact that most speleologists wear gloves that can be decontaminated suggests that standard personal hygiene practices (hand washing, bathing) likely represent a much more practical approach to limiting the spread of WNS on human skin.
In addition to chemical treatments, immersive heating of materials able to withstand submersion could be useful for reducing contamination by $G$. destructans spores. It is important to note that such conditions are not normally achieved in a standard washing machine, although sterilizing washing machines that can heat and maintain the temperature above $50{ }^{\circ} \mathrm{C}$ for twenty minutes would be a practical alternative. Given the difficulty in establishing and maintaining dry-air temperatures above $70{ }^{\circ} \mathrm{C}$ without laboratory-type controlled ovens or autoclaves, this mechanism of disinfection is not advised for anyone without access to, and training in the use of, such equipment. Regardless of these practical considerations, if heat treatment is the primary mechanism of disinfection, it is also important to consider the risks of contaminating external surfaces of containers, instruments, or surrounding surfaces. Limiting contact of contaminated gear or subsequent disinfection of such surfaces with effective chemical agents would help mitigate this risk.

Our chemical-disinfection experiments demonstrate the effectiveness of a number of agents that are known to be sporostatic but not sporicidal, including quarternary ammonium compounds and detergents (Russell, 1990). These results actually align well with those for bacterial spores and sporicidal agents (Russell, 1990 and references therein) and the work of Chaturvedi et al. (2011) against $G$. destructans. The effectiveness of these agents may well be due to a phenomenon by which these agents become attached to the spore coat and are hard to remove (other than by neutralization; Russell, 1990), suggesting that these agents do not act specifically on the spores, but rather act on germ tube formation during germination (Deacon, 2005). In all our assays, the presence of a long-chain alkyl group in the most effective antifungal agents suggests that such chemical structures play an important role in

\section{8- Journal of Cave and Karst Studies, April 2013}


preventing the growth of Geomyces spp. (Table 2). The specificity of such activity may help to identify whether Geomyces-restrictive antifungal agents could be identified for the in situ treatment of hibernating bats.

There were some differences between the results found in the disk-diffusion assay and the spore assay, specifically as they relate to bleach. These differences can probably be accounted for by adsorption of the reactive chlorite ions $\left(\mathrm{ClO}_{2}^{-}\right)$to reagents in the media. This effect was amplified by the addition of clays, sand, and silt to the media. Mud consists of insoluble clay particles that remain after speleogenesis. The composition of these muds depends on the rock formation from which they were derived. In the Ste. Genevieve Formation (used in these assays), these muds are primarily silica $\left(\mathrm{SiO}_{2}\right)$, but also contain kalsilite $\left(\mathrm{KAlSiO}_{4}\right)$, iron $\left(\mathrm{Fe}_{2} \mathrm{O}_{3}\right)$ and aluminum $\left(\mathrm{Al}_{2} \mathrm{O}_{3}\right)$ oxides (Preston and Denver, 1967). Such clays contain numerous reactive surfaces, such as hydroxyl $\left(\mathrm{OH}^{-}\right)$or siloxane $\left[\left(\mathrm{SiO}^{-}\right)_{n}\right]$ groups, which can be bound by reactive ions (Sposito et al., 1999). Indeed, such clays are often used as adsorption agents in a variety of settings, including hydrocarbon extraction and absorptive chemical liners (Sposito et al., 1999). It is therefore likely that such compounds adsorb the reactive ions of disinfectants, negating some of the antifungal properties of these agents. Although disk-diffusion assays yielded similar results for both $G$. pannorum and $G$. destructans, the sporicidal activity of agents differed for the two fungi, possibly due to differences in the spore coats. This assay involved treating spores with the agent of interest, thoroughly washing the spores, then culturing the washed spores. Differences in spore coats could result in differential adherence of certain compounds to the spores of the two species examined.

The chemicals chosen in the development of these protocols (Table 2) were based on their commercial availability and ability to be included in a disinfection protocol that could be carried out by untrained personnel in the field. Chemicals were also selected that could disinfect without damaging the potentially life-supporting materials of recreational cavers. Our data demonstrate the effectiveness of protocols that can be used on caving equipment to decontaminate Geomyces fungal spores from surfaces in a short time $(\sim 15$ minutes $)$ and that the chemicals did not significantly alter the strength of Sterling rope (Fig. 3). Our protocols and results led to the development of the USFWS standard decontamination protocols (http://www.fws.gov/ WhiteNoseSyndrome/cavers.html) and demonstrate the ability to kill all of $2.5 \times 10^{4}$ spores, an effective kill rate of greater than $99.995 \%$, although it is possible that this kill rate may actually be higher.

In the food and pharmaceutical industries, hygiene protocols aim not to sterilize pharmaceuticals and cosmetics, but to remove sufficient microorganisms to prevent human infections (Baird et al., 2000). As such, much lower concentrations of disinfectants, used for longer periods, may reduce the fungal spore burden down to a level that is considered safe (Gupta et al., 2001). At this time, no information is available about spore loading during human visits to a cave or the minimum infective dose of $G$. destructans to initiate WNS in bats or contaminate the cave environment. The spread of WNS along bat migration routes (Frick et al., 2010) and the lack of numerous geographic epicenters may also suggest that humanvectored transport of $G$. destructans may be rare. Nonetheless, until the exact mechanism of $G$. destructans transport and environmental survival is known, it is critical to remove the potential impact of human transport. However draconian the proposed decontamination measures seem, a high level of adoption within the caving community can ensure continued access to both popular recreational sites and demonstrate to landowners and management agencies the commitment of cavers to both protect the fragile underground wilderness and care for the only other mammalian species that penetrates as deeply into this subterranean world.

\section{ACKNOWLEDGEMENTS}

The authors thank Sterling Rope Company and Jim Ewing for their assistance in testing rope strengths following decontamination, PMI (LaFayette, Georgia), On Rope 1 (Chattanooga, Tennessee), and Inner Mountain Outfitters (Bethlehem, Georgia) for the generous donation of a variety of caving fabrics. This research was funded in part by the National Speleological Society WNS Emergency Fund and the US Fish and Wildlife Service.

\section{REFERENCES}

ASTM, 2002, Standard Practice for Determining Resistance of Synthetic Polymeric Materials to Fungi, West Conshohocken, Pennsylvania, American Society of Testing and Materials standard G21-09, 5 p.

Baird, R.M., Hodges, N.A., and Denyer, S.P., eds., 2000, Handbook of Microbiological Quality Control: Pharmaceuticals and Medical Devices, Boca Raton, Florida, CRC Press, 280 p.

Bauer, A.W., Kirby, W.M.M., Sherris, J.C., and Turck, M., 1966, Antibiotic susceptibility testing by a standardized single disk method: American Journal of Clinical Pathology, v. 36, p. 493-496.

Blehert, D.S., Hicks, A.C., Behr, M., Meteyer, C.U., Berlowski-Zier, B.M., Buckles, E.L., Coleman, J.T.H., Darling, S.R., Gargas, A., Niver, R., Okoniewski, J.C., Rudd, R.J., and Stone, W.B., 2009, Bat white-nose syndrome: an emerging fungal pathogen?: Science, v. 323, 227 p. doi:10.1126/science. 1163874

Chaturvedi, S., Rajkumar, S.S., Li, Xiaojiang, Hurteau, G.J., Shtutman, M., and Chaturvedi, V., 2011, Antifungal testing and high-throughput screening of a compound library against Geomyces destructans, the etiologic agent of geomycosis (WNS) in bats: PLoS One, v. 6, paper e17032, 6 p. doi:10.1371/journal.pone.0017032.

Chaturvedi, V., Springer, D.J., Behr, M.J., Ramani, R., Li, Xiaojiang, Peck, M.K., Ren, P., Bopp, D.J., Wood, B., Samsonoff, W.A., Butchkoski, C.M., Hicks, A.C., Stone, W.B., Rudd, R.J., and Chaturvedi, S., 2010, Morphological and molecular characterizations of psychrophilic fungus Geomyces destructans from New York bats with white-nose syndrome (WNS): PLoS One, v. 5, paper e10783, 12 p. doi:10.1371/journal.pone. 0010783 .

Daszak, P., Cunningham, A.A., and Hyatt, A.D., 2000, Emerging infectious diseases of wildlife-threats to biodiversity and human health: Science, v. 287, p. 443-449. doi:10.1126/science.287.5452.443. 
Evaluation of Strategies For the DeContamination of EQuipment for GEomyces destructans, the Causative agent of White-Nose SYNDROME (WNS)

Deacon, J.W., 2005, Fungal Biology, Indianapolis, Wiley-Blackwell, 384 p. Frick, W.F., Pollock, J.F., Hicks, A.C., Langwig, K.E., Reynolds, D.S., Turner, G.G., Butchkoski, C.M., and Kunz, T.H., 2010, An emerging disease causes regional population collapse of a common North American bat species: Science, v. 329, p. 679-682. doi:10.1126/ science. 1188594.

Gottlieb, D., 1950, The physiology of spore germination in fungi: The Botanical Review, v. 16, p. 229-257. doi:10.1007/BF02873609.

Gupta, A.K., Ahmad, I., and Summerbell, R.C., 2001, Comparative efficacies of commonly used disinfectants and antifungal pharmaceutical spray preparations against dermatophytic fungi: Medical Mycology, v. 39, p. 321-328.

Kunz, T., and Tuttle, M., 2009, Science Strategies for White Nose Syndrome. WNS Science Strategy II Meeting May 27-28, 2009, Austin, Texas.

Lorch, J.M., Meteyer, C.U., Behr, M.J., Boyles, J.G., Cryan, P.M., Hicks, A.C., Ballmann, A.E., Coleman, J.T.H., Redell, D.N., Reeder, D.M., and Blehert, D.S., 2011, Experimental infection of bats with Geomyces destructans causes white-nose syndrome: Nature, v. 480, p. 376-378. doi:10.1038/nature 10590

McGrain, P., and Denver, G.R., Jr., 1967, Limestone resources in the Appalachian region of Kentucky: Lexingon, Kentucky Geological Survey bulletin ser. 10, no. 4, 12 p.

Meteyer, C., U. Buckles, E.L., Blehert, D.S., Hicks, A.C., Green, D.E., Shearn-Bochsler, V., Thomas, N.J., Gargas, A., and Behr, M.J., 2009, Histopathologic criteria to confirm white-nose syndrome in bats: Journal of Veterinary Diagnostic Investigation, v. 21, p. 411-414. doi:10.1177/104063870902100401.
Puechmaille, S.J., Verdeyroux, P., Fuller, H., Ar Gouilh, M., Bekaert, M., and Teeling, E.C., 2010, White-nose syndrome fungus (Geomyces destructans) in a bat, France: Emerging Infectious Diseases, v. 16 , p. 290-293. doi:10.3201/eid1602.091391.

Russell, A.D., 1990, Bacterial spores and chemical sporicidal agents: Clinical Microbiological Reviews, v. 3, p. 99-119. doi:10.1128/CMR.3.2.99.

Savill, N.J., Shaw, D.J., Deardon, R., Tildesley, M.J., Keeling, M.J., Woolhouse, M.E.J., Brooks, S.P., and Grenfell, B.T., 2006, Topographic determinants of foot and mouth disease transmission in the UK 2001 epidemic: BMC Veterinary Research, v. 2, article 3, 9 p. doi:10.1186/1746-6148-2-3.

Sposito, G., Skipper, N.T., Sutton, R., Park, S.-H., Soper, A.K., and Greathouse, J.A., 1999, Surface geochemistry of the clay minerals: Proceedings of the National Academy of Sciences of the United States of America, v. 96, p. 3358-3364. doi:10.1073/pnas.96.7.3358.

USFWS, 2012, North American bat death toll exceeds 5.5 million from white-nose syndrome: [Arlington, Virginia, Office of Communications] http://www.fws.gov/whitenosesyndrome/pdf/WNS_Mortality_2012_NR_ FINAL.pdf [Accessed February 22, 2012]

Webb, R., Mendez, D., Berger, L., and Speare, R., 2007, Additional disinfectants effective against the amphibian chytrid fungus, Batrachochytrium dendrobatidis: Diseases of Aquatic Organisms, v. 74 p. 13-16. doi:10.3354/dao074013.

Wibbelt, G., Kurth, A., Hellmann, D., Weishaar, M., Barlow, A., Veith, M., Prüger, J., Görföl, T., Grosche, L., Bontadina, F., Zöphel, U., Seidl, H.-P., Cryan, P.M., and Blehert, D.S., 2010, White-nose syndrome fungus (Geomyces destructans) in bats, Europe: Emerging Infectious Diseases, v. 16, p. 1237-1242. doi:10.3201/eid1608.100002. 